\title{
Using CoRT Based Program to Improve Creative writing Skills of EFL Secondary Stage Students
}

\author{
Asmaa medhat Mohamed El-sherbeny
}

\begin{abstract}
The present study aimed at investigating the impact of using CoRT program to develop secondary stage students' creative writing skills. The targeted creative writing sub- skills were (flexibility, fluency, accuracy, and originality) the study adopted the quasi-experimental design. Using 60 1st year secondary stage students divided into two groups: an experimental group received the CoRT program and a control group that was taught in the regular method. Instruments designed and used in the study were a creative writing test and a rubric for scoring the students' creative writing performance. The experimental treatment was conducted during the second semester of the academic year 2017-2018 the results showed that there was statistically significant difference between the control and experimental groups on both instruments in favor of the experimental group. In addition, there were statistically significant differences between pre-and post-administration of both instruments on the experimental group in favor of the post administration. The results indicate that The CoRT program led to developing students' EFL creative writing skills.
\end{abstract}

Key words: EFL creative writing skills, the CoRT program.

\section{Introduction}

English is an international language that is spoken in many countries as a first, second or foreign language. It has established itself in recent decades as the common language of international communication. English language has become the language of knowledge since most of the human innovations in research, science, medicine, literature, and all other fields are written and documented in English In the context of education, English language skills have an essential role in helping learners develop

their thinking and creativity skills using several language processes such as, relating, commenting, connecting, predicting, recalling, comprehending, applying, associating, analyzing, synthesizing, evaluating and solving problem. Among these skills, writing skills is considered a thinking tool for language and creativity development.

Writing skill is the way with which individuals and institutions can communicate all over the world, and it is a great instrument for helping people to know more 
about others' way of thinking, in addition, creative writing skills consolidate concepts and ideas that allow peoples to write down their ideas and innovations. It helps to determine how to arrange actions in the innovative works. Throughout writing, one can translate his concepts and be able to logically persuade others. It is easier to test and evaluate the development of the individual's level when the person achieves noticed progress in written context.

In describing creative writing, Sak, (2010) asserted that creative writing classes provide an opportunity to develop confidence in presenting one's own work and critiquing others. Adults can explore interests while experimenting with self- expression and taking personal risks. Three elements of the topic (presentation, action, and interaction) were developed through which individual assessment, collaboration, and creativity could be. Mely (2009) asserted that teachers, as well as learners, should engage with extensive reading. He argued also that there are significant benefits to teachers if they participate in creative writing.

Haroon (2014) stated that creativity is an essential element that is obviously involved in the teaching learning process; particularly that learning is viewed as a creative process that involves students making information relevant by linking prior knowledge and new knowledge in a meaningful format. Shorofat (2007) pointed out that writing could be classified into two kinds: functional and creative. Creative writing is that kind through which individuals can convey what they have in their minds to others in an attractive literary style. It includes several genres such as writing stories, poems, plays and essays. Musa (2002) also, noted that creative writing is a distinguished academic activity and one of the complex mental processes which writers express their feelings and reactions. Ibnian (2009) defined creative writing as that kind of writing through which students express thoughts, opinions, solutions etc... in an attractive literary style, taking into account mechanics of writing.

Fortunately, a number of approaches, methods, and programs have been used to improve language learning in general and the creative writing skill in particular. One of the promising programs to develop creative writing is CoRT program. The CoRT program is considered the most famous among the thinking programes across the world. (CoRT) stands for (Cognitive Research Trust) an institution 
of cognitive research which was established by De Bono, a theorist, at Cambridge . It is an educational curriculum for direct teaching of thinking skills, divided into six modules each consists of ten lesson.

The CoRT 1 is Breadth which helps students broaden their perception. They should know more about each thinking situation after using the tools than they knew before they started. The CoRT 2 is Organization that gives students a variety of tools to organize their thinking. In addition, the CoRT 3 is Interaction that helps students observe the thinking involved in arguments, how a point of view is presented or defended, and the value and types of evidence. The CoRT 4 is Creativity in which students learn tools to generate fresh new solutions to challenges. The CoRT 5 is Information and Feeling tool to separate emotions from facts. Finally, the CoRT 6 is Action which begins with the purpose and ends with specific action steps for the implementation of the outcome .(Debono, 2009)

The tools in the CoRT 4 program are selected for improving creative writing sills for the first grade for secondary stage students .They include :Yes, no, po ( possible ),Stepping stone, Random input, Dominant idea ,Define the problem, Remove faults
,Combination, Requirements , and evaluation. The essence of the CoRT Thinking Method is to focus attention directly on different aspects of thinking and to translate these aspects into definite concepts tools that can be used deliberately .

The CoRT program features ways to help students with different abilities to use them effectively in academic and personal situations. In other words, The program helps all students including students with special needs and at-risk students (De Bono, 1998). After over 38 years of widespread use, the CoRT program is now considered a universal tool that is widely used in different cultures, situations, ages, and abilities. This program is being used in Australia, USA, Singapore, South Africa, UK, Ireland, Italy, Japan, Malaysia, Brazil, Canada, France, India, Malta, New Zealand, Philippines, Russia, and Venezuela.

The CoRT consists of 60 lessons divided into six parts. Each part comprises 10 lessons (Al Zyoudi, 2009; Jarwan., 2007). However, in the CoRT program the focus is on evolving the easy use of thinking skills by frequent exercise; thus, argumentation does not seem to be a major issue for evolving 
thinking skills. Therefore, it is shortened (Moseley, Elliott, et al., 2005). Nevertheless, Dingli (2001) pointed out that learning the CoRT skills helps students with different abilities to learn in order to gain suitable principles for long term education and also to deal with rapid changes in the twenty-first century.

The CoRT program helps students to collect, select and evaluate information. later, Moseley, Elliott, et al. (2005) reported that the CoRT program teaches a set of thinking "processes" defined by abbreviations for "creative and critical thinking"; processes that target the breadth in knowledge, organizing thinking and addressing them with proper knowledge .However, a few studies have used CoRT in the field of TEFL . This study attempts to investigate the effectiveness of using CoRT based program to improve creative writing Skills for the first grade secondary stage students.

\section{The CoRT program}

The CoRT program is one of the promising programs to improve creative writing skills which was designed by Edward de Bono and was first published in 1973. The name CoRT stands for Cognitive Research Trust which was established at Cambridge, England (Dingli, 2001), in 1976, his book 'Teaching Thinking' was published (one of 41 books which he has published on the topic, in 26 languages). (Murphy, Michelle, Bourne, Briggs, 1995)"The cognitive research trust (CoRT) program has been in use for over twelve years in a wide variety of schools in the wold (DeBono,1976). The notion of the program generally is practical thinking at the cognitive research trust to encourage the use of material with applicability in a wide variety of situations. Therefore, this program considers thinking is a basic process that can be taught and used across a wide variety of ages and abilities (Debonno,1985)

The idea that creative abilities are trainable emerged in the $1950 \mathrm{~s}$ when a few psychologists and creativity scholars such as. Guilford, Parne and Torrance disagreed with their colleagues who thought that creativity is a characteristic fixed at birth and which could not be increased deliberately. Instead, they viewed creativity as a common characteristic of all human beings rather than being a trait reserved to a few gifted individuals (Casanovas,2015). 


\section{CoRT4"creativity" program:}

The target program in this the study is CoRT 4 "creativity" is concerning with creative thinking for improving creative writing skills including lateral thinking which are Yes, no, po (possible ),Stepping stone, Random input, Dominant idea ,Define the problem ,Remove faults ,Combination, Requirements, and evaluation. The essence of the CoRT Thinking
Method is to focus attention directly on different aspects of thinking and to crystalline these aspects into definite concepts tools that can be used deliberately. This section is concerned with creative thinking including element of lateral thinking which students learn tools to generate fresh new solutions to challenges.

\section{The following lessons are emphasized}

\begin{tabular}{|c|l|}
\hline Lessons & \multicolumn{1}{|c|}{ The CoRT4 program } \\
\hline $\begin{array}{c}\text { Stepping } \\
\text { Stone }\end{array}$ & $\begin{array}{l}\text { A way of looking at things, used to judge ideas creatively (Po } \\
\text { = Possibly) }\end{array}$ \\
\hline $\begin{array}{l}\text { To use an idea creatively, as a stepping stone to other ideas. } \\
\text { Say/do something unlikely or outrageous as a way to move } \\
\text { beyond the current situation }\end{array}$ \\
\hline $\begin{array}{c}\text { Concept } \\
\text { Challenge } \\
\text { order to trigger new idea. }\end{array}$ & $\begin{array}{l}\text { A way of not taking things for granted. Looking at the A } \\
\text { accepted ideas and refuting/challenging them. It does not } \\
\text { matter if the original idea remains the best at the end of this } \\
\text { process) }\end{array}$ \\
\hline $\begin{array}{c}\text { Dominant } \\
\text { Idea }\end{array}$ & $\begin{array}{l}\text { Recognizing the main ideas behind a situation in order to not } \\
\text { be restricted by them }\end{array}$ \\
\hline $\begin{array}{c}\text { Define the } \\
\text { Problem }\end{array}$ & $\begin{array}{l}\text { An effort to define a problem exactly may lead to it being } \\
\text { easier to solve. What is the real problem here? How is best } \\
\text { defined? Not just by linguistics or semantics but by purpose } \\
\text { them. Faults may be obvious or they may be a matter of } \\
\text { omission. }\end{array}$ \\
\hline Remove faults & $\begin{array}{l}\text { Pick out all the faults in a given idea and remove is a limited } \\
\text { form of creativity to improve thinking }\end{array}$ \\
\hline combination & $\begin{array}{l}\text { Put to gather things that have existed separately to create } \\
\text { something that have a value more than the sums of its part. }\end{array}$ \\
\hline Requirements & $\begin{array}{l}\text { Considering requirements at the beginning of the process will } \\
\text { shape the ideas in a creative way }\end{array}$ \\
\hline Evaluation & $\begin{array}{l}\text { Look at the value of the idea, not so much in itself but in } \\
\text { relation to the situation. How does it fit the requirements? } \\
\text { What are the disadvantages? }\end{array}$ \\
\hline
\end{tabular}

Figure (1) lessons based on the CoRT4 program 
The CoRT based program is proper for helpining learners to use their thinking and imagination to write creatively. It would be appropriate to use this type of program in order to help student imagine and practice thinking so that it helps students improve their writing. Therefore, the purpose of this study was to investigate the impact of using CoRT based program to improve creative writing skills of EFL $1^{\text {st }}$ year Secondary stage students

\section{Review of literature\& studies}

A few numbers of studies have been carried out to evaluate, discuss or measure the value of CoRT based program in teaching and learning.

Nofel (2006) studied the effect of using CoRT 1 "Breadth", 2 "Organization" and "Creativity" on developing the creative thinking of the fourth year students in UNRWA Educational Sciences College in Amman, the results confirmed that teaching CoRT developed the students' originality, flexibility and fluency cited in AlFaoury, (2014).

Alzyuadi (2009) aimed at examining the effect of a creativity training program on the creativity thinking skills of students with learning disability of the fifth grade in $\mathrm{Al}$ Ain District. The sample of this study involve (32) students.
The results of this study approved that there were significant effect of a training program on the fluency, flexibility, and elaboration in favor of the experimental group

The study of Al-Muhtaseb (2010) examined the impact of integrating thinking skills in science textbooks on achievement in science, scientific skills and decision making ability among 7th graders in Palestine. The results verified that the integration of thinking skills in science content was effective in developing 7 th female students' achievement in science, scientific skills and decision-making ability.

The study of Abewickrama (2011) aimed at investigating the creativity of the learners of English as a second language at a state university in Sri Lanka. The sample consisted of 20 intermediate level second year undergraduates who were following the Core English Language (CEL) Level 4 course. The findings of the study showed that the respondents were sufficiently competent to create a higher number of responses and a considerable number of novel solutions on all the sub-tasks of the creativity test.

In Al-Edwan (2011), it was studied that the effectiveness of a training program based on CoRT strategies to develop the critical 
thinking of seventh grade students in history. The sample of this study included 163 seventh male and female students in Amman Second directorate. The study results approved that there are statistical differences in the critical thinking of seventh grade students in history that are related to teaching methodology and the method of the training program which used CoRT strategies.

Melhem et al (2013) aimed at enhancing the critical thinking skills among sixth grade students with learning difficulties in mathematics in Jordan by using the CoRT program. The findings indicated that the training program had a very large-sized effect on the participants' critical thinking.

Furthermore, Hanan (2014) identified the effect of utilizing CoRT program on developing creative thinking skills in mathematics for 6 th grade students. The sample consisted of two classrooms of 6th grade students with a total number of 70 students divided equally into two group, experimental and control from $\mathrm{Abu}$ Tamam High Basic School for females. The findings revealed that there were post-tests in favor of the post-test.

Al Faoury (2014) investigated the effect of teaching CoRT Program 4 entitled "Creativity", that stands for Cognitive Research Trust. The researcher aimed at teaching creative and critical thinking, to the gifted students' creative abilities in writing through wordless books. The experimental group consisted of 36 gifted students in Ein El-Basha Center of Gifted Students. The findings approved that the CoRT Program developed the gifted learners' creative abilities in writing English short stories (Cited in Abdel Haq \& Al-Mashaqba , 2015).

Tarqe (2014) investigated The CoRT program to measure its effects on enhancing critical thinking (CT) and improving motivation to learn for sixth grade student with Learning (LDs) in mathematics in Jordan. The experimental group consisted of 93 sixth-grade students from schools in First Amman Educational Directorate in Jordan. The results verified that the training program had a very large -sized effect on the participants' CT and MTL.

Cupta (2014) investigated the effect of De Bono's CoRT Thinking Program on the Concept Map Performance of Senior Secondary School students of grade IX and $X$ in relation to their level of intelligence. Two identical groups comprised of 51 respondents in each. The results observed that CoRT Thinking Program has significant 
effects on concept map performance. Level of intelligence has also been found to have significant effect on some component of concept map performance. Mustafa (2015) reported on a study which examined the use of creative thinking skills in academic essay writing at an Islamic higher learning institution. Two (2) groups of undergraduate students were involved in the study whereby one (1) group was given the treatment of Cognitive Research Trust (CoRT) program while another was taught academic writing conventionally. The results recommend that the aspect of academic writing process could benefit from the use of creative writing skills.

aims to investigate the
effectiveness of CoRT training program on the creativity of the Jordanian English language learners. Results: it revealed that there was a statistically significant difference at the level $(\alpha=0.05)$ in the mean scores between the experimental group and the control group in favor of the experimental group. Interestingly, the current study adopted the experimental design.
In the study of ALshurman, (2017) aimed to enhance the first part of the CoRT program for teaching thinking development of communication skills among a sample of students from $\mathrm{Al}$ alBayat University in Jordan. The sample included all the students enrolled in the training session. The findings showed that there were statistically significant differences between the pre and post measurements for members of the experimental group on the communication skills scale in favor of the post measurement.

Reviewing the literature, it is found that students were a weak in creative writing skills therefore, CoRT program are very beneficial for teaching EFL and may help students on improving creative writing skills.

\section{Pilot study}

In order to provide evidence for the problem of the study, the pilot study was conducted to a first year secondary stage students current level of EFl creative writing skills .A selected sample was taken from Bohut secondary school in Nabaroo City to check students creative writing performance on the first term exam, 2016 the sample included 30 students. 
Table(1) Students' performance in creative writing+

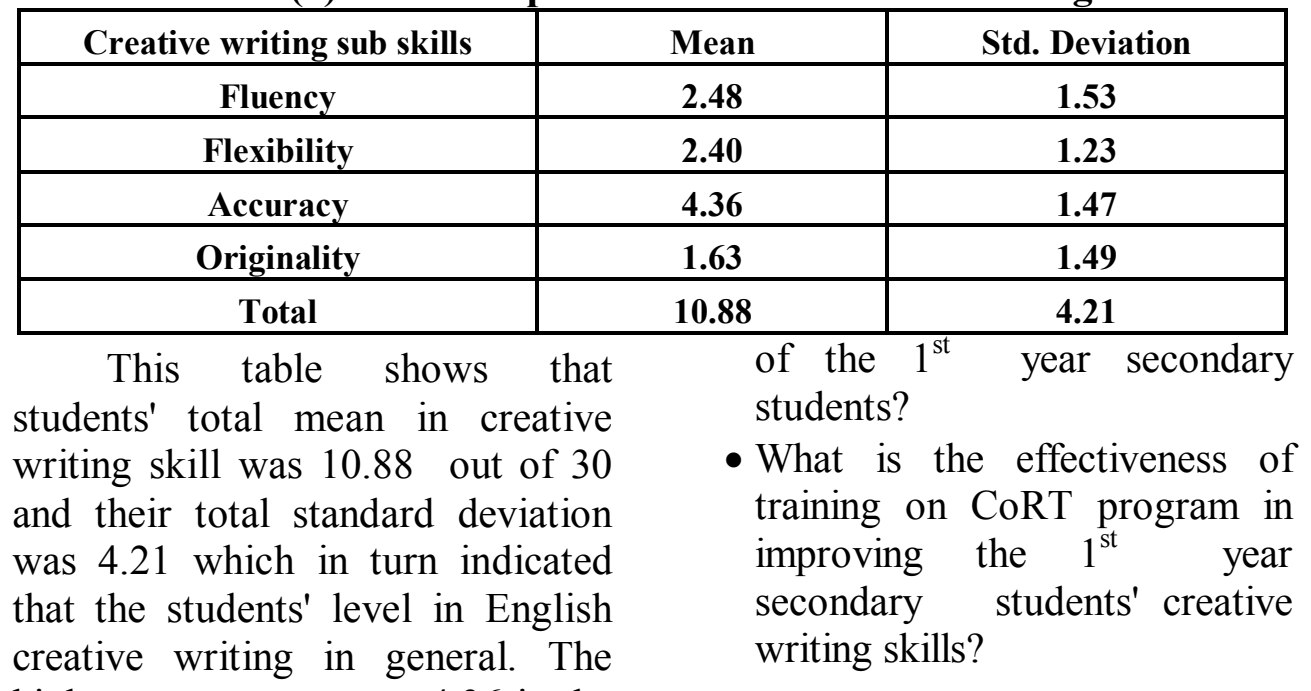

\section{Purpose} accuracy sub-skill while the lowest mean was 1.63 in the originality sub-skills this level may be due to a number of variables that include the lack of training in using appropriate learning strategies that improve creative writing skills.

\section{Problem of the study:}

Based on the literature review, and results of the pilot study, second year secondary students were not doing well in creative writing skill .They needed to develop their skills in creative writing. So, the current study investigated the effect of CoRT4 based program to develop their creative writing skills.

\section{Question}

- What are the component of CoRT based program to develop creative writing skills

The present study aimed at:

- Identifying creative writing skills of the first year secondary stage students.

- Designing a CoRT based program to improve creative writing skills of the second year preparatory female students.

- Determining the effectiveness of CoRT based program in improving creative writing skills.

\section{Hypotheses}

The study verified the following hypotheses:

- There is statistically significant difference at 0.05 level between the mean of the score of experimental group student and control group students in the post - administration of the 
creative writing skill test in favor of the experimental group students

- There is statistically significant difference at 0.05 level between the mean of score of pre-and post -administration of the creative writing skills test of the experimental group in favor of the post administration.

\section{The Methodology of the study:}

Methodology of the current study includes the participants, instruments, design and procedures followed to carry out the

\section{Participants}

The participants of the study are two $1^{\text {st }}$ year secondary classes from Bohut secondary school in Nabaroo city .One class of 30student represents the experimental group receiving the CoRT program Training. The other class of 30 students serves as the control group receiving the regular teaching.

\section{Design:}

The study adopted the quasi experimental design of the two groups of a sample of $1^{\text {st }}$ grade secondary students.

The frist group was Experimental group who studied the content of the target units in light of the CoRT program. The other group was Control group who studied the same content of the target unit using the regular teaching approach.

This design included the following variables: the independent variables which was The CoRT Based program and a dependent variable which was creative writing. The following figure shows the design of this study:

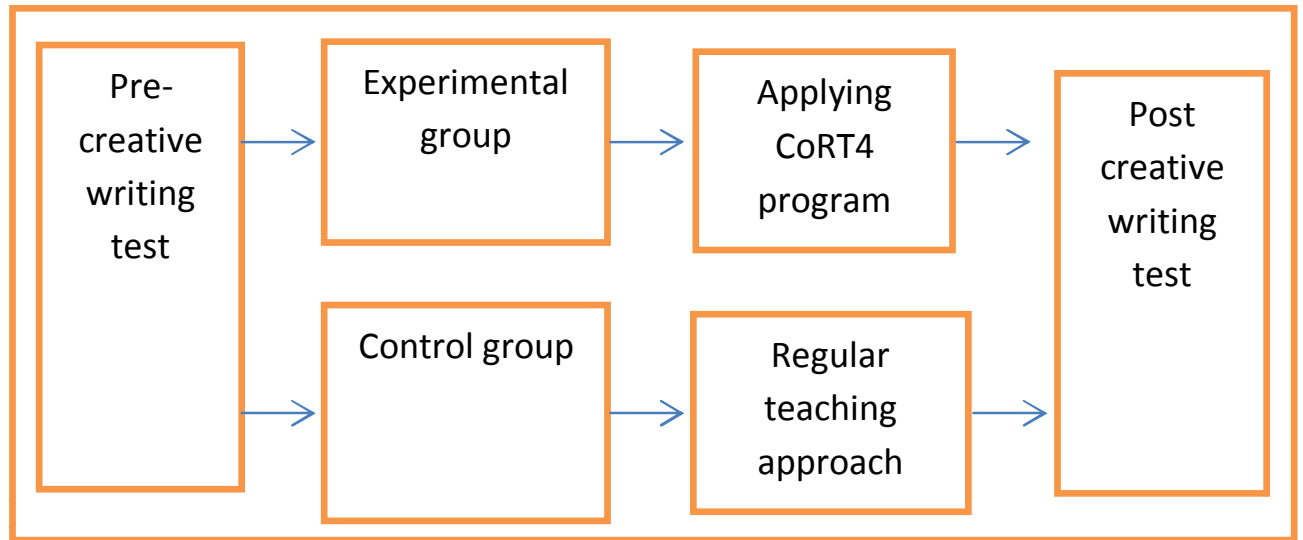


- A Creative writing test assessing $1^{\text {st }}$ grade secondary student's creative writing before and after administrating the treatment.

- A rubric for scoring the creative writing test.

The Delimitations of the study:

The present study is delimited to:

- Some creative writing skills necessary for first year for secondary stage students.

- A sample of the $1^{\text {st }}$ grades of secondary school students.

- CoRT4 program which in creativity

\section{Results and discussions}

Results were statistically analyzed in terms of the hypotheses. they were discussed in the light of the theoretical back ground and related studies. Results of the study were separated according to the hypotheses.

Results related to the first hypotheses

1. Verifying the first hypothesis: The first hypothesis stated that "There is a statistically significant difference at the 0.01 level between the mean score of the experimental group students and that of the control group on the post administration of the creative writing test in favor of experimental group students"

The T-test was used to compare the difference between the mean score of the students in the creative writing test in the experimental and the control group

Table (3) Comparing the writing performance of the two groups on the creative writing post -test.

\begin{tabular}{|c|c|r|c|c|c|}
\hline \multirow{2}{*}{ Skills } & \multicolumn{2}{|c|}{ Experimental group } & \multicolumn{2}{c|}{ Control group } & \multirow{2}{*}{ T-value } \\
\cline { 2 - 5 } & Mean & \multicolumn{1}{c|}{ Sd. Devi. } & Mean & Sd. Devi. & \\
\hline Fluency & 6.82 & 2.04 & 4.02 & 2.23 & $5.05^{*}$ \\
\hline Flexibility & 6.37 & 2.70 & 3.20 & 2.26 & $5.14^{*}$ \\
\hline Accuracy & 8.96 & 2.44 & 6.66 & 2.54 & $4.45^{*}$ \\
\hline Originality & 5.73 & 2.91 & 2.93 & 1.76 & $4.51^{*}$ \\
\hline Total Skills & 27.89 & 8.46 & 16.82 & 6.92 & $4.53^{*}$ \\
\hline
\end{tabular}

Significant at 0.01 level *

The Results in table (3) illustrate that the mean score of the experimental group was greater than that of the control group. It was clear that there was a statistically significance difference at 0.01 level between the mean score of the experimental group and that of the control group on the post-administration of the 
creative.Also, the table shows that the students mean score in the overall post creative writing test in the experimental group was 27.89 compared to(16.82) for the control group. This indicates that the CoRT program helped to improve the experimental group creative writing performance.

The increase of the students' level in experimental group can be interpreted that students in the experimental group were active in using the CoRT specially questions led to their thinking. Activities associated with the CoRT4 programs led to this increase and made this difference.

Group work and pair work made the students more cooperative with each other. These activities include discussions, reporters' note book, questioning, and thoughtful interaction during lessons.

\section{Results related to the second hypotheses}

The second hypothesis stated that "There is statistically significant difference at the 0.01 level between the mean score of the experimental group students on the pre and Post-administration of the creative writing test"

In order to verifying the second hypothesis, the t-test was used to show the difference between the main score of the experimental group students on the pre and post administration of the creative writing test.

Table (4) Creative writing performance of the experimental groups students on the pre and post-administration of the creative writing test.

\begin{tabular}{|l|c|c|c|c|c|}
\hline \multirow{2}{*}{ Skills } & \multicolumn{2}{|c|}{ Pre experimental group } & \multicolumn{2}{c|}{ Post experimental group } & \multirow{2}{*}{ T-value } \\
\cline { 2 - 5 } & Mean & Std. Devi. & Mean & Std. Devi. & \\
\hline Fluency & 4.02 & 2.23 & 6.82 & 2.04 & $* 5.68$ \\
\hline Flexibility & 3.14 & 1.98 & 6.37 & 2.70 & $* 6.24$ \\
\hline Accuracy & 6.75 & 1.56 & 8.00 & 1.92 & $* 3.10$ \\
\hline Original & 2.82 & 1.74 & 5.73 & 2.91 & $* 4.95$ \\
\hline Total Skills & 17.35 & 6.34 & 26.94 & 7.96 & $* 5.85$ \\
\hline
\end{tabular}

* Significant at 0.01 level

Table (4) indicates that there was a statistically significant difference at 0.01 level between the attained mean score of the experimental group in the pre-post administration in the creative writing sub skills and the total score of the experimental group. Results in Table (4) show that the students' mean score of creative writing sub skill of the experimental group in the post- 
test were increased (26.94) compared to(17.35) in the pretest. This indicates that the CoRT program helped to improve the experimental group creative writing sub-skills.

The increase in the mean score of the experimental group in the post-test implies that the student' level in overall creative writing has been developed due to the training.

The paired t-test results indicate that the differences between the mean score of the experimental group student in the pre and post- creative writing test was statistically significant at $<0.001$ level in favor of the post administration which, in turn, indicates the effectiveness of the CoRT program training in enhancing the creative writing skills of the students. Estimating the effect size ( $\eta 2$ ):

In order to determine the effect size of the CoRT based program the Eta square was used.

Table (4) The effect size of using CoRT based program

\begin{tabular}{|c|c|c|}
\hline Skills & Level of effect size & Eta square \\
\hline Fluency & High & $0.53^{*}$ \\
\hline Flexibility & High & $0.57^{*}$ \\
\hline Accuracy & Mid & $0.38^{*}$ \\
\hline Originality & High & $\mathbf{0 . 4 6}^{*}$ \\
\hline Total & High & $\mathbf{0 . 4 9}^{*}$ \\
\hline
\end{tabular}

Significant at 0.01 level *

Eta square was used to measure the effect size of the experimental treatment (CoRT program). Results in this table illustrate the eta square value for each creative writing sub-skills and the total of these sub-skills. It is obvious that all of these values ranged from (0.38 to 0.57$)$ which refer to a high effect size for all the creative writing sub-skills and the total score except the mid effect size of the accuracy. This indicated that the CoRT based program had high effect in improving the experimental group creative writing and its sub-skills.

\section{Results of the study}

Within the limitation of the study and on the basis of the results obtained, the following conclusion have been reached 
1- The obtained results showed that the creative writing skills is a complex activity that require much time and practice on learners' part and a lot of experience and guidance on the teachers 'part .pupils should know that the CoRT4based program is not a waste of time. Each lesson of CoRT 4 contributes to effective creative writing.

2- While providing CoRT 4 lessons by teacher, students could not understand all of written comments, which could be due to illegibility. The results showed that the most teachers' written feedback was teachercentered. It made student passive and dependent on teacher.

3- There is more need to help students fully utilize the CoRT based program given to achieve improvements in their creative writing. Teacher need to response and judge on students as a work in progress rather than as a finished product.

4- The lessons of CoRT4 program "creativity" necessary for first year secondary students' creative writing skills.

5- The experimental group students outperformed their counterparts of the control group in the writing skill test. This was indicated by the significant differences between the mean scores of the two groups.

6-The experimental group students' mean scores in the post application of the writing test were better than their mean scores in the pre-application of the test. So, the CoRT4 based program (creativity) were effective on improving first year secondary students creative writing skills.

\section{Suggestions for further research:}

Further investigation is needed to determine other lessons of CoRT program that could help in 
improving students' creative writing skills and sub- skills

1- Providing students with CoRT4 and other learning strategies of thinking that promote their thinking and encourage them to better creative writing

2- Encouraging teachers to reinforce their skills by using various strategies to make their students as enjoyable as possible.

3- Investigating other techniques and methods to teach creative writin

4- Teacher should prepare students to reach a deeper level of thinking to write creatively unlike the traditional methods of writing.

5- Conducting a follow-up study on this research in order to see whether the CoRT program training has the same influence on other language skills (reading, listening and speaking).
6- Administering the CoRT based program-based learning to different stages (i.e., primary and preparatory). Applying the experimental treatment on larger

\section{References}

Abeywickrama, K. R. W. K. H. (2011). Learner creativity-a potential facilitator for oral task performance? (Doctoral dissertation),7(8) 307-323, University of Sabaragamuwa

Abed-Aziz\&Hanan,M, (2014).

Effect of utilizingCoRT program in developing creative thinking skills in mathematics $\mathrm{f}$ or 6th grade students. Unpublished MA Thesis. College of Education at the Islamic

Al-Jallad, M. (2006). The effectiveness of using the CoRT program on developing the creative thinking skills among the female students of the Arabic language and the Islamic studies at Ajman 
university network of science

and technology. Journal of

Umm Al-Qura University of

Educafional, Social and

Humanitarian Sciences, 18(2), 147-180.

Al-Sobh, M. A., \& Al-Abed Al-

Haq, F. (2012). Online linguistic messages of the Jordanian secondary students and their opinions toward a web-based writing instructional EFL program (Special issue). International Journal of Humanities and Social Science, 2(6), 288-299.

Alshurman, W. M. (2017). The Effects of the First Part of the CoRT Program for Teaching Thinking (BREADTH) on the

Development

of

Communication Skills among a Sample of Students from Al alBayt University in Jordan. Educational Research and Reviews, 12(2), 73-82.

Al-Faoury, O. H., \& Khwaileh, F. (2014). The Effect of Teaching
CoRT Program No.(4) Entitled"

Creativity" on the Gifted Learners' Writings in Ein ElBasha Center for Gifted Students. Theory \& Practice in Language Studies, 4(11).

Al-Edwan, Z. S. M. (2011). The Effectiveness of a Training Program Based on Cognitive Research Trust Strategies to Develop Seventh Grade Students' Critical Thinking in History Course. Journal of Social Sciences, 7(3), 436.

Al-Muhaqba, N. J. A., \& Al-Haq, F. A. A. (2015). The Effect of a Pictorial Story-Based Instructional Writing Program on Enhancing the English Writing Performance of Jordanian Secondary Students. US-China Foreign Language, 44.

Al-Muhtaseb, S. (2010). The Impact of Integration of Three Parts of CoRT Program for Teaching Thinking in Science Textbooks on Achievement, 
Scientific Skills \& Decision

Making Ability among 7th

Graders in Palestine. An-Najah

University Journal for

Research, 24(8), 2311-2334.

Al Zyoudi, M (2009). Effects of a creativity training program for Breadth and Organization on the creativity thinking skills of students with learning disability" Issue NO. 26. Journal of Faculty of Education. UAE

Bakr, S. (2004): The Efficacy of some Proposed Activities for Developing

Thinking of English Learners at the Preparation Stage. Unpublished M.A. Thesis,University of Ayn AlShams.

Dingli, S. (2001). Brief literature review. Action Research Final report. The Edward de Bono Institute for the Design and Development of Thinking. University of Malta. Pridobljeno, 2(5), 2011.
'Debono,E.(2009)"CoRT1 Breadth thinkingtools , Retrieved from www.deBonoFor Schools.com Lib DeBono, E. (1995). Parallel thinking (from socratic to the debono).London:Penguin

Books.

De Bono, E. 1985. Six hinking HatsLondon: Penguin Books. bono, E. (2004). Edward De Bono Authorized Website. Retrieved February from http://www.edwdebono.comlde bonolindex.html

De Bono, E. (2004). Edward de Bono biography. Retrieved July, 22, 2004 retrieved from: http://www.edwarddebono.co.

De Bono, E. (1976). Teaching thinking. London: Penguin Books

De Bono E (1998). CoRT Program $\mathrm{f}$ or Teaching Thinking. (Translatedby Nadia AlSrur et. Al.), Amman. Al FKR house of publication.

DeBono, E. (1995). Parallel thinking (from socratic to the 
debono).London:Penguin

Books

Haroon, S., (2014) The Effect of using the Problem SolvingStrategy on developing the Creative Writing Skills and Interest of preparatory pupils towards EFL, MA.Institute of Educational Studies, Curriculum and Instruction Dept., Cairo University cited in Tawfik,W,E.(2016) The Effect of Critical Reading on Developing 1 st Year Preparatory Students' English Creative writing skills, Ain Shams University, Faculty of Education

Hinnant, B. (1993).A study of Debono's PMI Thinking Tool as a Means of Enhancing Student Writing Performance. Retrieved from http://www. eric. ed. Gov,cited in ELfoary, o.A The Effect of Teaching CoRT Program No. (4) Entitled "Creativity" on the Gifted Learners' Writings in Ein El-
Basha Center for Gifted Students

Hmeadat,S,.R. (2016). The Effect of the Cognitive Research Trust Program for Development of Thinking Skills on the Achievement of the Jordanian English Language Learners. The Arab Journal of Sciences \& Research Publishing, 2 (1).

Ibnian, S. (2009) The Effectiveness of a Program based on Problem Solving to enhance the tenth grade students Creative Writing skills and attitudes, the Educational Studies Institute, Cairo University.

Jarwan, F. (2007). Teaching thinking concepts and applications (3 ed.).Amman Dar Al-Fakr of Publishers and DistributorsJennifer W. Waring (20 Jarwan., F. (2007). Teaching thinking concepts and applications (3 ed.). Amman Dar Al-Fakr of Publishers and Distributors. Jarwan, F. (1999). 
Teaching thinking: Concepts and applications. Al Ain, UAE: University Book House.

Kumari, S., \& Gupta, K. (2014). Effectiveness of Creativity Training Program on Concept Map Performance of Secondary School Students. Int. J. Interdisciplinary

Multidisciplinary Stud, 1(5), 127-131.

Khetab N (2004). The effect of the First Part of CoRT (the field of cognition) and the second part (organization) on Developing the Creative thinking and the Self-Concept among a Jordanian Sample of Students with Learning Difficulties (Unpublished $\mathrm{PhD}$ thesis). The University of Jordan, Amman, Jordan

Moseley, D., Baumfield, V., Elliott, J., Higgins, S., Newton, D. P., Miller, J., \& Gregson, M. (2005). Frameworks for thinking: A handbook for teaching and learning.

Cambridge University Press.

Martínez Casanovas, M. (2015). Improving Creativity Training. An examination of the effects of delivery method and problem realism on creative performance in post-training ideation(Doctoral dissertation, Universitat Ramon Llull).

Melhem, T. Y., \& Isa, Z. M. (2013). Enhancing critical thinking skills among students with learning difficulties. International Journal of Academic Research in Progressive Education and Development, 2(4), 151-

Mansoor, A. (2010) Teaching Creative Writing to University, Second Level Language Learners in Pakistan University of Sussex, English, Essex House, University of Sussex, Falmer, Brighton, BN1 9QQ United Kingdom.

Maley, A. (2009). Creative writing for language learners (and 
teachers). Teaching EnglishBritish Council \& $B B C$.

Retrievedfromhttps://www.teac hingenglish.org.uk/article/creati ve-writing-language-learnersteachers

Musa, M. (2002) the effect of a proposed program in developing some creative writing skills in the fields of story and narrative awareness for 5 the primary pupils, studies in curriculum and instruction, the Egyptian council for curriculum and instruction, Ain Shams University, Cairo

Murphy, Patricia. \& Michelle, Selinger. \& Bourne, Jill. \& Briggs, Marry. (1995). Subjects learning in the primary curriculum: Issues in English, science and mathemati, The Open University, Routledge

Nofel, M. (2006). Athar Barnamaj CoRT fee Tanmeat Al- Tafkeer Al-Ebda'ee Lada AienahMen
Al- Mutafawegeen tahseelianFee Kulliat AlOloom Al-Tarbaweah AlJame'ah. (The Effect of CoRT Program on Developing the Creative thinking for aSample of Excellent Students in Educational Sciences College). Paper presented at the First Arab Conference for CoRT Experts,Meredian Hotel, Amman, 19-20, July, 6-48.

Shorofat, A. (2007). The effect of using the brainstorming strategy on developing ninth grade students' creative writings skills in Arabic language. Unpublished doctoral dissertation). The University of Jordan

Sak, U., \& Oz, O. (2010). The effectiveness of the Creative Reversal Act (CREACT) on students' creative thinking. Thinking Skills and Creativity, 5(1), 33-39 